\title{
PENGARUH SPUTTERING TIN TERHADAP KEKASARAN, KEKERASAN PERMUKAAN MATERIAL AISI316L
}

\author{
Jemssy Ronald Rohi ${ }^{1}$, Priyo Tri Iswanto ${ }^{1}$, Tjipto Sujitno ${ }^{2}$, Erich Umbu Kondi M. ${ }^{1,3}$ \\ ${ }^{1}$ Departemen Teknik Mesin dan Industri, Fakultas Teknik, Universitas Gadjah Mada, \\ Jl. Grafika No.2, Yogyakarta, 55281 Indonesia \\ ${ }^{2}$ PusatSains dan Teknologi Akselerator, BATAN, Jl. Babarsari Kotak Pos 6101 Ykbb, Yogyakarta 55281 \\ ${ }^{3}$ Universitas Nusa Cendana, Jl. Adi Sucipto Penfui No.85001, Lasiana, Klp. Lima, \\ Kota Kupang, Nusa Tenggara Timur \\ e-mail :1jemssyr@gmail.com
}

\begin{abstract}
AISI $316 L$ is widely used for implantation in orthopedic surgery due to its good corrosion resistance, mechanical properties and low cost. However, AISI 316L is not well suited for biocompatibility with the body, so implant material with AISI 316L can't be used for a long time. One way to improve the corrosion resistance and mechanical properties of AISI $316 \mathrm{~L}$ is to perform a surface treatment such as sputtering. This study discusses the effect of deposition sputtering TiN of 60, 90, 120 and 150 minutes on roughness and surface hardness at a ratio of argon gas and nitrogen to $80 \%$ Ar:20\% N2. The results of the surface roughness value of the TiN sputtering layer deposited to AISI 316L for 60, 90, 120, and 150 minutes were $0.02 \mu \mathrm{m}, 0.04 \mu \mathrm{m}, 0.06 \mu \mathrm{m}$, and $0.04 \mu \mathrm{m}$ respectively. This shows that the coating time of TiN in AISI 316L has no significant influence on value of surface roughness. Surface hardness results at 60, 90, 120, and 150 minutes were obtained with $268 \mathrm{HVN}, 275 \mathrm{HVN}, 278 \mathrm{HVN}$ and $282 \mathrm{HVN}$. Increased hardness value, as the TiN thin layer has a higher hardness value compared to AISI 316L. The longer the deposition time, the more layers are formed and the layer becomes thicker. With the thickness of the layer, the density at the grain boundary increases. Because the higher density leads to grain growth, in which form micropores.
\end{abstract}

Key words :Sputtering TiN, Roughness, Hardness, AISI $316 L$

\section{ABSTRAK}

AISI 316L banyak digunakan untuk tujuan implantasi dalam operasi bedah ortopedis karena ketahanan korosi dan propertis mekanik yang baik serta harga yang murah, tetapi AISI 316L kurang baik sifat biokompatibilitasnya dengan tubuh sehingga untuk material implan dengan bahan AISI 316L tidak dapat digunakan untuk jangka waktu lama. Salah satu cara yang dilakukan untuk meningkatkan ketahanan korosi dan sifat mekanis dari AISI 316L adalah dengan cara melakukan perlakuan permukaan misalnya sputtering. Penelitian ini membahas efek dari durasi waktu deposisi Sputtering TiN dari 60, 90, 120, dan 150 menit terhadap kekasaran dan kekerasan permukaan dengan perbandingan gas argon dan nitrogen 80\% Ar : 20\% N2. Hasil nilai kekasaran permukaan lapisan sputtering TiN yang dideposisikan pada AISI

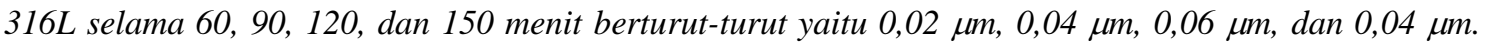
Hal ini menunjukkan bahwa waktu pelapisan TiN pada AISI 316L tidak memiliki pengaruh yang signifikan terhadap nilai kekasaran permukaan. Hasil kekerasan permukaan pada 60, 90,120, dan 150 menit yang di peroleh masing-masing adalah 268 HVN, 275 HVN, 278 HVN, dan 282 HVN. Kenaikan nilai kekerasan karena lapisan tipis TiN memiliki nilai kekerasan yang lebih besar dibandingkan dengan AISI 316L. Semakin lama waktu deposisi berarti lapisan yang terbentuk akan semakin banyak dan lapisan semakin menjadi tebal, dengan semakin tebalnya lapisan, maka kerapatan batas butir menjadi semakin meningkat, karena kerapatan semakin tinggi menyebabkan terjadinya pertumbuhan butir yang disertai pembentukan pori-pori mikro.

Kata kunci: Sputtering TiN, Kekasaran, Kekerasan, AISI 316L

\section{PENDAHULUAN}

Material untuk bahan endoprestik atau material implant harus memenuhi 2 persyaratan yaitu biocompatible (dapat diterima oleh tubuh) dan sifat mekanik yang sesuai dengan kondisi tubuh manusia [1]. Syarat mendasar dari 
biomaterial berbasis logam adalah sifat tahan karat yang tinggi. Sifat utama yang harus dimiliki oleh biomaterial berbasis logam adalah kesesuaian dengan sel hidup (excellent biocompatibility). Stainless steel adalah material yang sudah sangat lama dikenal dan paling disukai untuk piranti ortopedik fiksasi internal karena ketahanan korosi yang tinggi, sifat mekaniknya yang baik, harganya tidak mahal dibandingkan dengan kobaltkhrom, titanium dan paduannya, serta biokompatibel [4]. AISI 316L banyak digunakan untuk tujuan implantasi dalam operasi bedah ortopedis karena ketahanan korosi dan propertis mekanik yang baik serta harga yang murah, tetapi AISI 316L kurang baik sifat biokompatibilitasnya dengan tubuh sehingga untuk material implan dengan bahan AISI 316L tidak dapat digunakan untuk jangka waktu lama karena pada lingkungan cairan tubuh (body fluid) terjadi korosi lokal serta adanya peristiwa pelepasan ion menuju jaringan disekitar implan sehingga dapat menimbulkan ancaman baru bagi pasien [9].

Khrom dan nikel dikenal karosinogen, dan mereka tidak hanya ditemukan dalam jaringan sekitar piranti cangkok, tetapi juga dalam sampel darah dan urin, sering pada tingkat lebih tinggi dari pada individu profesional yang terkena logam ini. Salah satu cara yang dilakukan untuk meningkatkan ketahanan korosi dan sifat mekanis dari AISI 316L adalah dengan cara melakukan perlakuan permukaan (surface treatment) misalnya sputtering. Sputtering merupakan proses penyisipan atom target (bahan pelapis) pada permukaan substrat dengan cara menembakkan ion-ion berenergi tinggi pada permukaan target yang menyebabkan atom-atom permukaan target terurai dan menyisip pada permukaan substrat. Adanya perbedaan potensial dengan substrat, atom-atom yang terurai tersebut mengarah dan terdeposisi pada permukaan substrat. Deposisi lapisan tipis Titanium Nitrida (TiN) memiliki sifat keras, tahan korosi, tahan abrasi, tahan suhu tinggi, koefisien gesek rendah, biokompatibel dan memiliki sifat mekanis yang baik [11].

Proses sputtering termasuk salah satu metode PVD (Physical Vapor Deposition), sering disebut sebagai ion plating (IP) atau vacum plating. PVD adalah teknologi pelapisan atau deposisi uap fisik untuk memindahkan bahan lapisan ke substrat dalam kondisi vakum. PVD telah terbukti mampu meningkatkan kekerasan permukaan baik itu bahan logam, non logam, keramik maupun polimer. Sputtering adalah proses pengeluaran atom dari permukaan suatu material yang dihasilkan dari benturan antar partikel dengan energi yang besar. Atom-atom dari permukaan target dapat terlepas akibat ion yang dipercepat menumbuk permukaan target melalui proses transfer momentum.

Metode Sputtering ini dapat diterapkan pada hampir semua material seperti logam, bukan logam, jenis paduan, oksida, karbida, nitride, dan polimer [2]. Penelitian tentang Sputtering [5] telah diteliti oleh Wen dkk, 2010 menunjukkan bahwa deposisi lapisan tipis sebesar 1,8 $\mu \mathrm{m}$ pada permukaan sehingga menghasilkan perubahan tegangan sisa tekan atau tarik, kekasaran permukaan, peningkatan kekerasan, penurunan laju keausan dan laju korosi pada permukaan substrat. Hal tersebut dipengaruhi juga oleh konfigurasi lapisan, struktur mikro dan ukuran butir deposisi lapisan tipis. Peningkatan kekerasan terjadi apabila ada perubahan tegangan sisa tekan yang dapat menghambat pergerakan dislokasi $[8,10]$

Dari uraian di atas serta penelitian yang relevan dan pernah dilakukan, maka penelitian ini bertujuan untuk 
mempelajari pengaruh perlakuan permukaan sputtering TiN dengan variasi waktu 60, 90, 120, dan 150 menit agar dapat memperoleh data parameter proses waktu sputtering yang optimum dengan perbandingan gas argon $80 \%$ Ar : $20 \% \quad \mathrm{~N}_{2}$ terhadap kekasaran permukaan dengan target angka kelas kekasarannya adalah N1 dengan harga kekasarannya 0,025 $\mu \mathrm{m}$ dan kekerasan permukaannya. untuk aplikasi bahan biomaterial alternatif. material AISI 316L dengan perlakuan Sputtering TiN diharapkan dapat diaplikasikan pada biomedis.

\section{METODE PENELITIAN}

\section{Preparasi Spesimen}

Spesimen yang digunakan dalam penelitian ini yaitu stainless steel 316L berbentuk plat dengan tebal $3 \mathrm{~mm}$ kemudian di potong secara manual dengan ukuran $2 \times 2 \mathrm{~cm}$ masing-masing sebanyak yang dibutuhkan, selanjutnya permukaan dihaluskan dengan kertas amplas dibantu alat orbital sander dengan grade amplas 400, 600, 800, 1000, 2000 dan 3000. Setelah di haluskan dengan amplas, selanjutnya spesimen di finishing menggunakan autosol metal polish untukmenghilangkan goresan dan membuat permukaan spesimen lebihhalus atau menyamakan kekasaran mula-mula dan menkilap. Adapun target kekasaran permukaan yang diharapkan dari pemolesan adalah $0,05 \mu \mathrm{m}-0,1 \mu \mathrm{m}$ sebelum di lakukan proses sputtering.

Spesimen yang sudah halus dan mengkilap dicuci dalam cairan alkohol dan digetarkan dalam ultra sonic cleaner selama kurang lebih 10 menit selanjutnya dikeringkan. Spesimen yang sudah dipreparasi disimpan dengan dibalut tisu pada wadah yang kedap udara agar terhindar dari proses oksidasi dan siap untuk dilakukan Sputtering.

\section{Perlakuan Spesimen}

Spesimen yang sudah dipreparasi permukaannya di berikan perlakuan dengan proses sputtering TiN dengan durasi waktu masing-masing spesimen yaitu 60, 90, 120, dan 150 menit dengan perbandingan gas argon dan nitrogen $80 \%$ Ar : $20 \% \mathrm{~N}_{2}$. Alat sputtering terdiri dari tabung reaktor dari stainless steel yang dilengkapi dengan sebuah jendela kaca, pemegang target dan pemegang substrat, catu daya arus searah, alat ukur arus, tegangan dan vakum, pompa vakum (turbo), pemanas substrat dan pendingin target. Target diletakkan pada katoda, sedangkan substrat diletakkan pada anoda. Tabung reaktor divakumkan dengan pompa difusi hingga tekanan 2,4 × $10^{-3}$ mbar. Setelah pompa vakum difusi mencapai tekanan yang dikehendaki, kemudian gas argon sebagai gas sputter dan gas nitrogen sebagai gas reaktif dialirkan melalui kran, sehingga tekanan gas di dalam tabung reactor akan naik menjadi $7,9 \times 10^{-2}$ mbar. Setelah itu menghidupkan penyedia daya tegangan tinggi DC dengan tegangan $5 \mathrm{kV}$ dan arus yang digunakan yaitu $10 \mathrm{~mA}$.

\section{Pengujian}

Pengujian kekasaran permukaan dilakukan dengan alat contact stylus profilometer (Surfcom 120 A, Advanced Metrology system, UK) yang diambil 1 titik pada tiap permukaan spesimen. Parameter yang digunakan dalam pengambilan data kekasaran yaitu cut off $0,800 \mathrm{~mm}$, length $8 \mathrm{~mm}$ dan meas-mag 2000. Data nilai kekasaran yang diperoleh yaitu nilai kekasaran rata rata $(\mathrm{Ra})$ yang diperoleh dari tiap spesimen.

Pengujian kekerasan akan dilakukan dengan metode uji kekerasan mikro vicker dan menggunakan indentor berbentuk piramida yang terbuat intan dan dasarnya berbentuk bujur sangkar. Pengujian menggunakan standar ASTM E384 dengan pemberian beban 100 gram selama 10 detik. Data diambil sebanyak 3 kali setiap permukaannya. 


\section{HASIL dan PEMBAHASAN}

\section{Kekasaran Permukaan}

Hasil uji kekasaran rata-rata pada baja AISI 316L yang telah dilapisi titanium nitrida, disajikan pada Gambar 4. Nilai kekasaran lapisan sputtering TiN yang dideposisikan ke baja AISI 316L selama 60 menit, 90 menit, 120 menit, dan 150 menit berturut-turut yaitu $0.02 \mu \mathrm{m}, 0.04$ $\mu \mathrm{m}, 0.06 \mu \mathrm{m}$, dan $0.04 \mu \mathrm{m}$. Sedangkan nilai kekasaran permukaan baja AISI 316L tanpa perlakuan yaitu $0.05 \mu \mathrm{m}$. Dari hasil pengujian kekerasan diperoleh bahwa nilai kekasaran terendah diperoleh pada waktu pelapisan selama 60 menit. Namun, jika dibandingkan dengan nilai kekasaran yang lain, perbedaan nilai kekasaran yang diperoleh tidak besar. Perbedaan terbesar antara nilai kekasaran rata-rata tertinggi dan terendah yaitu $0.04 \mu \mathrm{m}$. Hal ini menunjukkan bahwa waktu pelapisan titanium nitrida pada baja AISI 316L tidak memiliki pengaruh yang signifikan terhadap nilai kekasaran permukaan. Hal ini terjadi karena lapisan titanium yang dideposisikan pada proses sputtering sangatlah tipis yaitu 4,5 $\mu \mathrm{m}$, dengan ukuran jari-jari atom titanium sebesar $140 \mathrm{pm}$ dan jarijari atom nitrogen sebesar $65 \mathrm{pm}$, kecenderungan atom-atom titanium dan nitrogen akan membentuk profil permukaan yang sesuai dengan profil permukaan baja AISI 316L. Secara sederhana, nilai kekasaran rata-rata pada permukaan hasil lapisan sangat dipengaruhi oleh kehalusan permukaan baja AISI 316L ketika preparasi spesimen uji [7].

\section{Kekerasan Permukaan}

Pengujian dilakukan dengan metode vickers dengan perbandingan nilai durasi sputtering TiN pada waktu 60, 90, 120, dan 150 menit. Hasil pengujian kekerasan diambil rata-rata dari 3 kali pengujian kekerasan dan disajikan dalam grafik Gambar 5. Gambar 5 menunjukkan bahwa adanya pengaruh perlakuan sputtering TiN meningkatkan kekerasan pada permukaan. Nilai kekerasan tertinggi teletak pada durasi waktu 150 menit sebesar 282 HVN. Nilai kekerasan tersebut menunjukkan bahwa adanya peningkatan kekerasan permukaan dengan penambahan durasi sputtering TiN pada material 316L. Peningkatan nilai kekerasan baja tahan karat AISI 316L yang dilapisi titanium nitrida selama 60, 90, 120 dan 150 menit secara berturut-turut yaitu 5,67 \%, 8,1 \%, 9,1 \%, dan 10,35 \%.

Peningkatan nilai kekerasan tertinggi didapat dengan waktu deposisi selama 150 menit, dengan kenaikan nilai kekerasan sebesar 10,35 \% dari material 316L yang belum diberi perlakuan sputtering TiN.

Kenaikan nilai kekerasan baja AISI 316L yang telah dilapisi karena lapisan tipis titanium nitrida memiliki nilai kekerasan yang lebih besar dibandingkan dengan baja AISI 316L, dikarenakan proses sputtering TiN maka terbentuk lapisan Titanium nitrida yang mampu memperbaiki sifat mekanis material berupa kekerasan yang disebabkan oleh adanya tegangan sisa yang terbentuk pada lapisan. Kekerasan meningkat seiring dengan berkurangnya ukuran butiran dan fraksi volume yang lebih tinggi pada batas butir [3]. Hal ini yang ditandai dengan adanya perubahan warna pada permukaan lapisan yang diberi perlakuan.

Semakin lama waktu deposisi berarti lapisan yang terbentuk akan semakin banyak dan lapisan semakin menjadi tebal. Dengan semakin tebalnya lapisan, maka kerapatan pada batas butir menjadi semakin meningkat. Karena kerapatan semakin tinggi akan menyebabkan terjadinya pertumbuhan butir yang disertai pembentukan kekosongan dan pori-pori mikro [6].

\section{KESIMPULAN}


Sputtering TiN dapat membuat kekerasan permukaan Aisi 316L meningkat. Semakin lama durasi sputtering TiN lapisan yang terbentuk akan semakin banyak dan lapisan semakin menjadi tebal. Dengan semakin tebalnya lapisan, maka kerapatan pada batas butir menjadi semakin meningkat. Pengaruh sputtering TiN paling optimum berada pada durasi 60 menit sebesar 268 HVN sedangkan kekerasan paling maksimum berada pada 150 menit sebesar 282 HVN. Waktu pelapisan sputtering TiN pada baja AISI 316L tidak memiliki pengaruh yang signifikan terhadap nilai kekasaran permukaan.

\section{UCAPAN TERIMAKASIH}

Penulis mengucapkan terima kasih kepada pemberi dana penelitian PDUPT UGM dan penulis juga mengucapkan terima kasih kepada PSTA-BATAN dan laboratorium bahan teknik departemen teknik mesin dan industri UGM yang telah memfasilitasi penulis dalam melakukanperlakuan sputtering TiN dan pengujiannya terhadap penelitian ini.

\section{DAFTAR PUSTAKA}

[1] Cahyanto, Arief. 2009. Makalah, Universitas Padjajaran, Bandung.

[2] Grainger, S., Blunt, J., 1999. Engineering Coatings-Design and Application, 2nd ed., Ed., Woodhead Publishing Ltd.

[3] Hetal, S,. Vipin, C,. Jayagantha, Davinder, K. 2010. Microstructural Characterizations and Hardness Evaluatinof DC Reactive Sputtered CrN Thin Films on stinless Steel Substrate. Indisn acamedyof Sciences 103-110.

[4] Yeung, K.W.K. R.W.Y. Poon, P.K. Chu, C.Y. Chung, X.Y. Liu, W.W. Lu, D. Chan, S.C.W. Chan, K.D.K. Luk, K.M.C. Cheung. 2007. Journal of Biomedical Materials Research Part A DOI 10.1002/jbm.a, 403-414

[5] Wen, M. Q. N. W. X. Meng, W. T. $\mathrm{Yu}, \mathrm{S}$. X. Zheng, Mao, M. J. Hua. 2010. Growth Stress and Hardness of Reactively Sputtered Tungsten Nitride Thin Films, Surface and Coating Technology 205. pp.19531961,

[6] Ohring, M. 1992. The Materials Science of Thin Films. Academic Press, New Jersey.

[7] Salahudin. Xander, 2014. Analisis Sifat Fisik Lapisan Tipis Titanium Nitrida Pada Baja AISI 410 Yang Dilapis Dengan Metode Sputtering. Prosiding SNST ke-5 Tahun 2014, Fakultas Teknik Universitas Wahid Hasyim Semarang. ISBN 978-60299334-3-7

[8] Shah, H. N., Chawla, V., Jayaganthan, R., and Kaur, D., $2010 . \quad$ Microstructural Characterization and Hardness Evaltio of D.c. Reactive Magnetron Sputtered CrN Thin Film of Stainless steel Substrate, Bulletin Materials Science, Vol. 33, No. 2, pp. 103-110.

[9] Sridhar, T. M., Mudali, Kamachi, U., Subbaiyan, M. 2003. Corrosion Science, 45 237-252.

[10] Stueber , M., Holleck, H., Leiste, H., Seemann, K., Ulrich, S., and Ziebert, C. 2009. Concept for the Design of Advance Nanoscale PVD Multiplayer Protective Thin Films, Journal of Alloysand Compounds483, pp. 321-333.

[11] Wang, L., Su, J. F., Nie, X., 2010. Corrosion and Tribological properties and impact Fatigue Behaviors of TiN and DLC Coated Stainless Steel in simulated Body Fluid Environment. Surface \& Coatings Technology 205, pp.15991605.

[12] Wirjoadi, Siswanto, B., Sudjatmoko. 2009. Analisis Sifat Mikro Lapisan Tipis TiN Pada 
Substrat AL Hasil Plasma Sputtering.Buku I Prosiding PPI PDIPTN Pusat Teknologi
Akselerator dan Proses Bahan BATAN Yogyakarta, 14 Juli 2009.

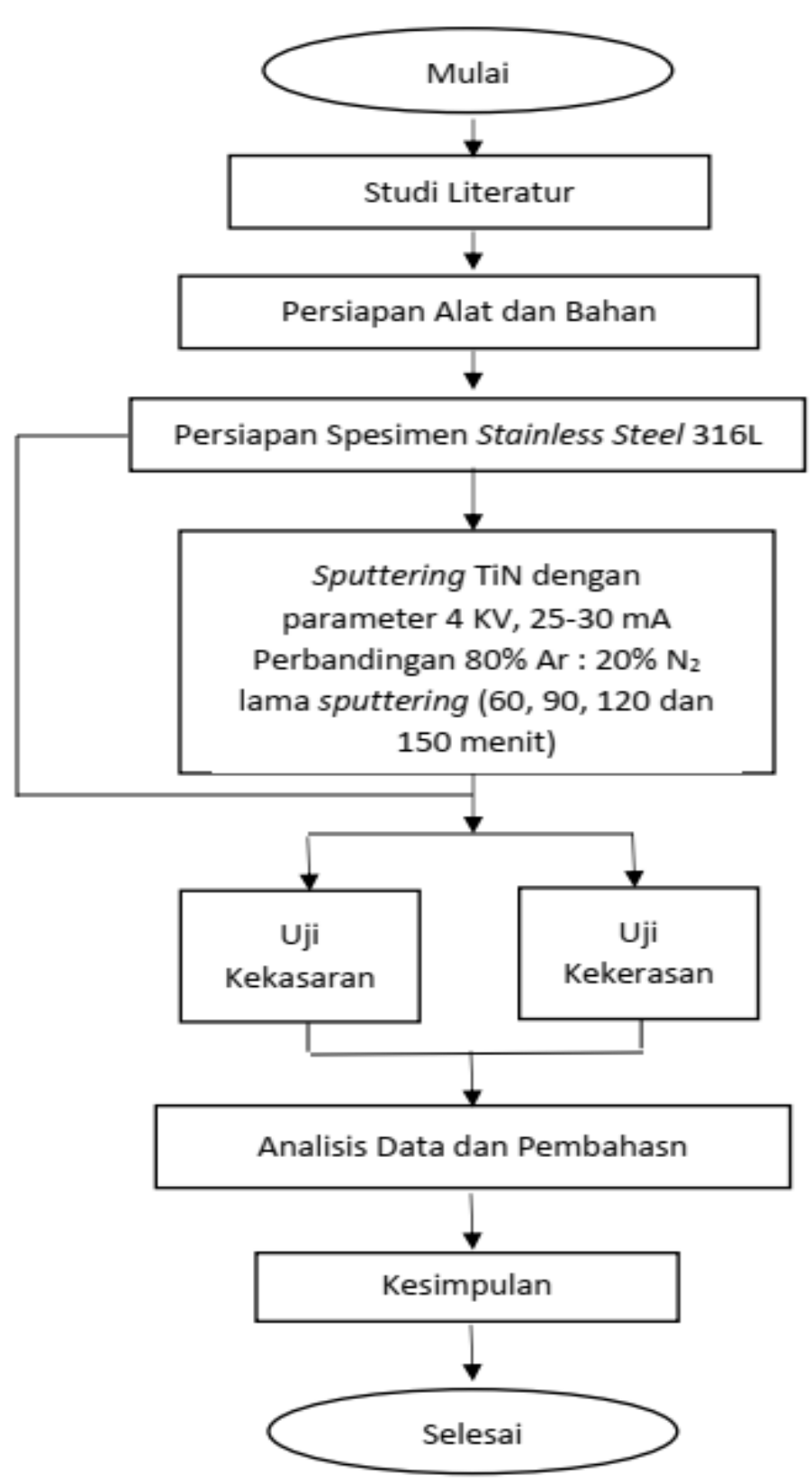

Gambar 1. Diagram alir penelitian 


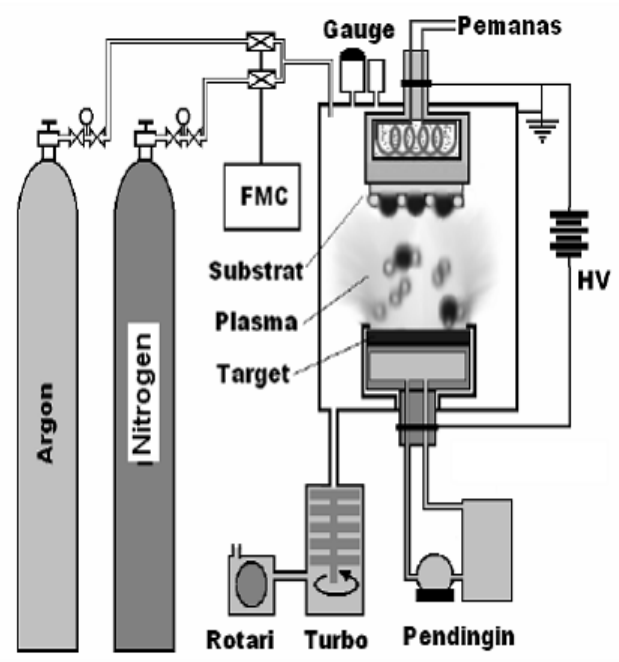

Gambar 2. Skema peralatan plasma sputtering DC [12].

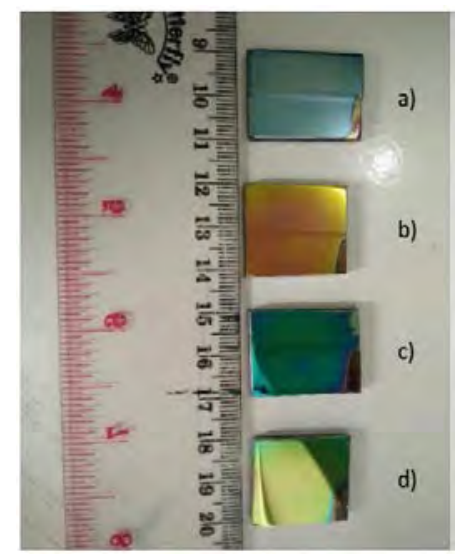

Gambar 3. Permukaan spesimen AISI 316L setelah perlakuan sputtering TiN dengan variasi waktu deposisi (a) 60 menit, (b) 90 menit, (c) 120 Menit, (d) 150 menit

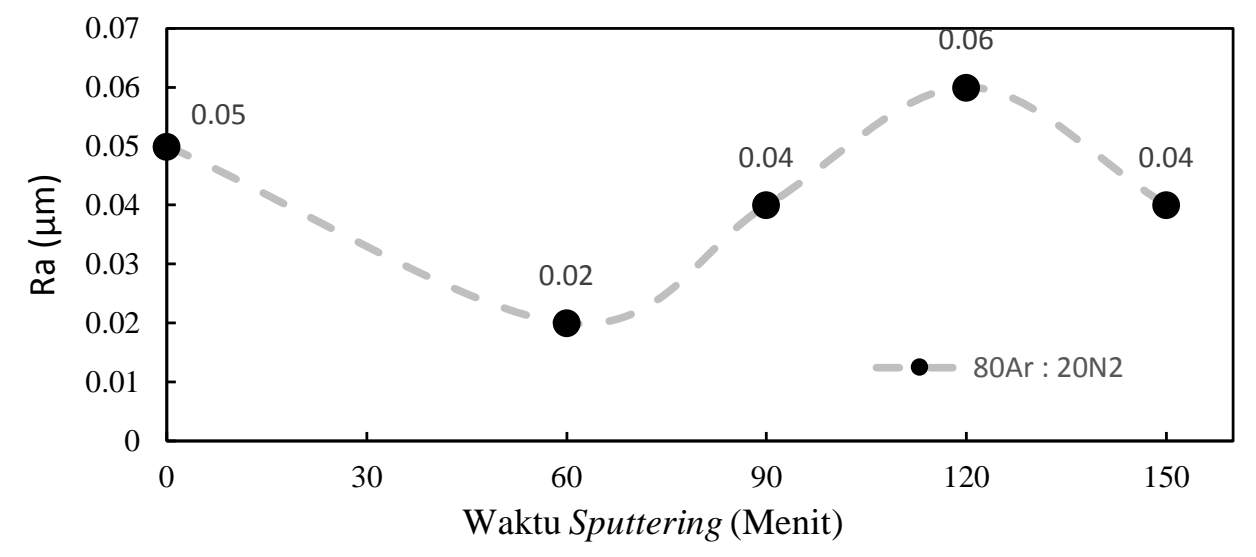

Gambar 4. Grafik pengaruh waktu pelapisan sputtering TiN terhadap nilai kekasaran permukaan 
Jenssy Ronald Rohi dkk, Pengaruh Sputtering Tin...

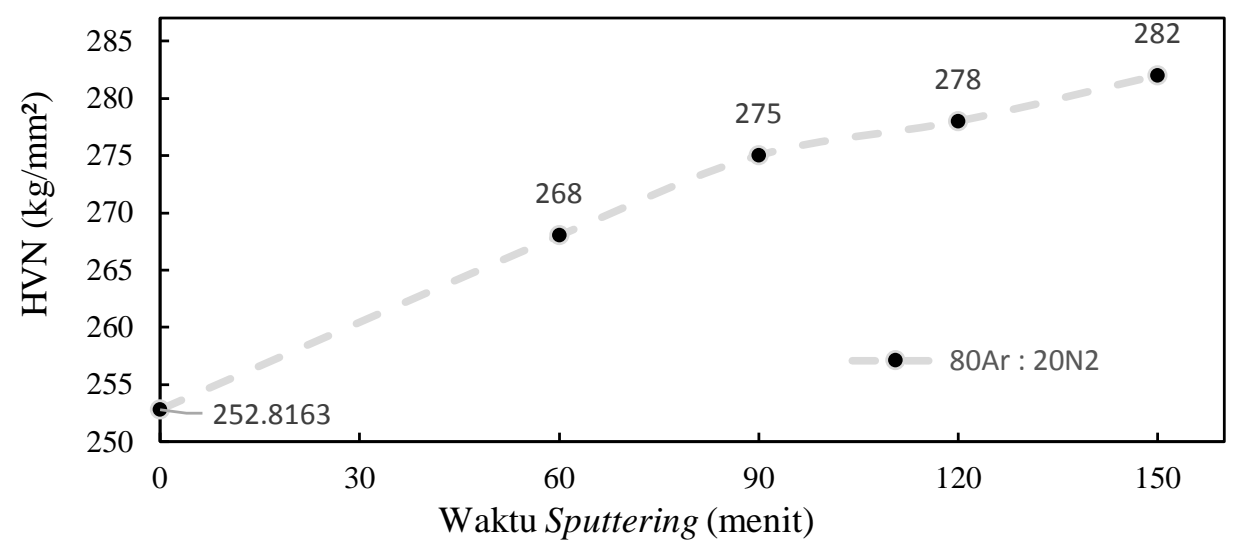

Gambar 5. Grafik pengaruh waktu pelapisan sputtering TiN terhadap nilai kekasaran permukaan 